\title{
Beyond Safe, Sane, and Consensual: Navigating Risk and Consent Online for Kinky Gay and Bisexual Men
}

\author{
Liam Wignall, $\mathrm{Ph} . \mathrm{D}^{1}$ \\ Bournemouth University (UK) \\ liamwignall@gmail.com
}

\begin{abstract}
Kink practitioners have adopted phrases, like "safe, sane and consensual" (SSC), to describe a non-pathological approach in considering risk and harm in kink practices. However, little is known about how risk and consent are negotiated online, particularly when the kink activities occur in private rather than the public or semi-public spaces of kink community venues or events. Drawing on 30 in-depth interviews with self-identified kinky gay and bisexual men, this article examines how risk and consent are discussed when organizing kink sessions through online platforms. Most participants were unaware of SSC or alternatives. Instead, participants employed diverse methods of negotiating consent and risk which predominantly involved indepth communication online. Interestingly, participants were more concerned with the risks associated with meeting others online, such as catfishing, than the risks involved with kink. Finally, some participants described a laissez-faire approach to their kink sessions through not planning or discussing risk and consent beforehand
\end{abstract}

\section{Introduction}

Kink is a spectrum of sexual or erotic activities outside normative versions of sex, undertaken for sensory, emotional, or intellectual pleasure. It tends to include a combination of the exchange of power, or perception of this, the infliction/receiving of pain, the wearing of gear, or the fetishization of body parts or objects. Kink can be practiced individually or in groups and can be organized into communities and subcultures. It is consensual, with a shared understanding that the activities are kinky. This definition of kink, alongside multiple alternatives (e.g. Moser \& Kleinplatz, 2007; Newmahr, 2011; Sprott \& Williams, 2019; Weinberg et al., 1984), place significant emphasis on consent.

The need for the centrality of consent is partly explained as resistance to early conceptualizations of kink as pathological (Shindel \& Moser, 2011), the placement of kink in the Diagnostic and Statistical Manual of Mental Disorders (DSM) (see Kreuger 2010a; b), and the cultural misconception of kink being a form of abuse (Bezreh, Weinberg \& Edgar, 2012). Activities such as the infliction of pain or role-playing with power may appear abusive (Pitagora, 2013), yet the consensual nature of the activities and emphasis on trust in these dynamics differentiate kink from abuse. While there are some activities which play on the edge of consent and risk (Newmahr, 2011), and this power dynamic can be abused (e.g. Dunkley \& Brotto, 2019; Kieran \& Sheff, 2016), as it can be in non-kink settings (e.g. Beres, 2007), kink can be a healthy expression of sexuality or leisure pursuit (Prior \& Williams, 2015; Sprott \& Williams, 2019).

\footnotetext{
${ }^{1}$ Acknowledgements: Many thanks to the attendees at the Positive Sexuality Conference 2020, Burbank, CA, for their feedback where many of the ideas in this article were discussed.
} 
Communicating the importance of consent in kink, alongside the navigation of risk, to kinky and non-kinky audiences was popularized initially through the language of safe, sane, and consensual, abbreviated to SSC (Williams et al., 2014). SSC was quickly adopted as a mantra for kink practitioners, activists, and the academic community (Langdridge \& Barker, 2007) as a simple and accessible way of countering the pathological framing of kink in broader culture. However, it was not intended to be a slogan for how kink should be practiced. As the creator of the term SSC stated: "Once an idea is reduced to a slogan that can fit on a button or T-shirt, no one can control its meaning" (Stein, 2002, p. 3).

SSC became used as a way of distinguishing between acceptable and unacceptable forms of kink practices (Downing, 2007), leading to the policing and delegitimization of extreme kink activities which played on the boundary of safety and consent (Newmahr, 2011). Some critics argued that SSC, and similar phrases like Risk Aware Consensual Kink (RACK), led to the "vanillafication" of kink, making kink align more with non-kink practices (e.g. Williams et al., 2014). The word "sane" is also problematic in this context (Downing, 2007). Yet research on kink still frames SSC as the most popular way that practitioners negotiate kink (Langdridge \& Barker, 2007).

More recently, Williams et al. (2014) proposed "Consent, Communication, Caring and Caution" (4Cs) as a framework for negotiating kink participation. The central tenets of consent and caution (safety/risk-awareness) are still present, but the 4Cs highlight the importance of communication within BDSM (Kaak, 2016), and the necessity of caring about partners both emotionally (Lindemann, 2011) and socially (Wignall \& McCormack, 2017). While the 4Cs is still relatively new, it provides a more open space to negotiate the complexities involved in kink. Yet, there is a need to move beyond discourses which distinguish between good/bad kink (Downing, 2007) to instead focus on how risk and consent are negotiated by kink practitioners. Some research has highlighted how this is done for kink organizations and clubs (e.g. Sagarin et al., 2019; Weiss, 2011), but less is known about how individuals who engage in more casual forms of kink navigate risk and consent (Coppens et al., 2020; Zambelli, 2017).

While kink venues maintain an important status within kink communities (Steinmetz \& Maginn, 2014), changing queer landscapes and the flourishing of technology has provided alternative pathways for individuals to engage in kink (Simula, 2019; Wignall, 2017). Contrary to older narratives of needing to be invited into a community or having to earn one's leathers (Rubin, 1991), individuals can permeate the boundaries of kink subcultures more easily by engaging with kink-oriented socio-sexual networking sites (SSNS), creating online profiles to explore these online kink spaces and interact with others (Graham et al., 2015; Wignall, 2019). Indeed, individuals can utilize the internet to research and learn about kink at their own pace, find others to engage in kink with, and explore kink communities (Döring, 2009; Wignall, 2019). In this article, I examine how kinky individuals negotiate risk and consent when arranging kink scenes online in private, rather than in kink venue settings.

\section{Method}

Data come from a larger study exploring the experiences of kinky gay and bisexual men $\mathrm{n}=30)$. Participants' ages ranged from 21 to $62(M=27.63)$, all participants were UK residents at 
the point of data collection. 27 participants were Caucasian, and 3 participants identified as bisexual. Participants identified with various kinky roles, including Leatherman, pup, and rigger. Most participants $(n=25)$ identified with a switch role, with 5 participants identifying with more dominant roles and 7 identifying with more submissive roles.

To recruit participants, the author created a profile on geolocation hook-up apps and SSNS aimed at gay and bisexual kinky men. A message template providing details of the research was sent to prospective participants. For those who displayed interest, further information, including an information sheet and consent form, were given. Participants were also recruited through snowball sampling of established individuals within various kink communities.

Participants identified as kinky but differed in levels of immersion into kink communities. As such, participants were labelled as either a community member or noncommunity participant. A holistic approach was undertaken to identify these two groups of participants, drawing on participants' understandings of kink; their SSNS profiles; and selfidentification. Community members framed kink as a socio-sexual activity, invested in their online profiles (multiple profile pictures; friends linked to their profiles; profiles containing demographic information; interaction with online forums), described how they had multiple kinky friends and attended kink events, and identified as part of a kink community. Noncommunity participants described kink as primarily a sexual activity, did not provide as much detail in their SSNS profiles, did not describe connections to kink communities, and actively distanced themselves from a community label. Participants were evenly split across the two groups.

Participants differed with their levels of real-world kink experience, ranging from the smallest of two years' experience to the most experienced participant with 20 years of experience $(M=5.9$ years $)$.

Interviews lasted approximately 60 minutes and covered a plethora of topics related to kink identities, communities, and activities, as well as participants' interactions with kink online platforms. Interviews were analyzed inductively using thematic analysis (Braun \& Clarke, 2006), with initial codes identified, grouped together through focused coding, and finally arranged into potential sub-themes and themes. The coding team consisted of a researcher who is familiar with kink practices and is established within kink communities, and a researcher with some knowledge of kink practices. The results were also discussed with five of the participants in the study who agreed with the findings. Ethical approval was granted from the University of Sunderland.

There are limitations of this study. Recruiting participants for research on kink is notoriously difficult (Weinberg, 2006). The sample consisted of gay and bisexual cisgendered white men from the UK primarily due to the author's existing contacts in these networks. As such, research is needed on the experiences of consent for other kink demographics. 


\section{Results}

Despite the popularity of SSC and similar frameworks, 25 of the 30 participants had never heard the phrase SSC before, or alternatives including RACK or the 4Cs. Epitomizing responses to questions about the terms, David said, "No idea what those terms are", while Thomas said, "I've not heard of them."

The remaining five participants could only offer vague descriptions of the terms and did not use them. For example, Mark said, "I'm aware of the concepts of SSC and RACK, but I've never heard much about them... I know kink has a long and varied history, but I don't really know anything about it." Luke said, "I'm aware of the concepts, but I wouldn't use the terms." While not knowing what it was, Sam said, "I've heard of safe, sane and consensual, but don't really know what it is. You can sort of work it out though." Ryan knew about the terms in context, saying, "I've heard of SSC, as opposed to BDSM being abuse? I don't know RACK though." Oscar had a negative association of SSC, saying, "I usually find people who use SSC are the people to avoid. I've heard people use the language, but it's not something I use myself. It reminds me of D\&D [drug and disease free] on profiles." While a lack of knowledge on terminology is understandable for non-community participants, it is noteworthy for community participants, given how SSC is somewhat labelled as the cornerstone of kink (Langdridge \& Barker, 2013). This speaks to a potential disconnect between dominant framings of kink and how some practitioners negotiate their play outside of community venues.

With these scripts absent, I now focus on how participants understood risk in terms of their kink practice. Three themes were identified from transcripts: navigating online safety; the importance of sustained communication; and unstructured approaches.

\section{Navigating Online Safety: Evaluating Kink and Non-Kink-Related Risk Factors}

When asked about negotiating kink on SSNS, participants predominantly focused on the risks associated with hooking up online generally, such as "catfishing" or sexual coercion (Lauckner et al., 2019), rather than negotiating risks involved in kink. Participants identified tactics used to ensure people were being truthful in these online environments. For example, George said, "You need to chat to people online for a bit. I normally ask for multiple pictures or very difficult pictures to forge, like their name on their foot. I've always been careful about who I talk to." Drawing on previous experiences, Stephen said, "I ask people to take a picture with the date on it. The first person I messaged online was a catfish. I drove to meet him, and they were a fake, so I learned quickly to check people out." Trevor described the techniques he used:

I check they're real by asking them to write the date on a piece pf paper and take a picture, or draw a picture on a piece of paper with the date, to work out they are the person they say they are.

Participants identified how continued communication helped decipher the realness of the person. For example, Lloyd said, "I don't play with anyone until I've spoken to them for a while, to make sure they're not crazy, going to abuse me, rob me or harm me in anyway." Similarly, 
Harry said, "I speak to people for ages online first. You can work out if they're real, and a bit about their personality... it makes me feel safer."

Sam and Fred were the only participants who mentioned using social media when chatting to potential kink hook ups online. Sam said, "I might add them on Facebook at some point because that adds another level of realness. If they have a profile with friends and pictures, you will think they're more real." Fred described feeling more relaxed seeing others' social media, saying," I don't normally let people stay over the first time I've met them. Unless I've had lots of conversations with them, or you have them on Facebook or something and you can see their jobs and friends."

Finally, some participants described precautions taken when meeting for kink hook ups again, these focused on the risks associated with meeting people online more generally rather than meeting for kinky sex. For example, Neville said, "If I am going somewhere new, I would scribble a note of my location and call the police if I don't get back in time." Similarly, Mark said, "I meet people in public, so if you say no, you're not jumping straight into their car. I don't have rules, but I'd like to feel safe, not too dark or lonely, somewhere I could tell the police about." Fred described how his somatotype was important when meeting others, saying, "Rightly or wrongly, most guys I meet I think I can physically take them on - I'm quite muscular." Fred felt more secure thinking if he ended up in a risky situation, he would be able to get out of it through brute force.

\section{The Importance of Sustained Communication}

Good communication was deemed the most important factor when arranging kink sessions through SSNS. Communication beforehand helped navigate the risks involved in kink activities, identify mutual kink interests, negotiate consent, limits and create safe words, and establish trust. However, this occurred in a more conversational way and developed organically from participants' thinking about the potential risks involved.

Most participants described sustained communication with potential kink hook-ups. For example, Thomas said, "I normally have a lot of chat beforehand. I wouldn't put myself in a vulnerable position at first." Similarly, Harry said, "I make sure I talk to people a lot beforehand - what our kinks are, different levels of experience, and some limits." While participants did not want "endless chat", they recognized the importance of clear communication beforehand. However, for some participants, there was a balance between just enough communication and too much, with Kyle saying he did not "want to plan the scenes, because then they would feel too contrived." Here, communication should be used to arrange kinky sex, but not plan exactly what would happen. As Oscar highlighted, kink can be "spontaneous."

This type of communication - discussing interests and things they will not do beforehand - is how participants navigated consent. However, when describing the context or the purpose of these conversations, no participant explicitly used the word consent. Instead, these conversations were described as making participants feel comfortable about meeting up and a way of agreeing which activities, they would engage in. Terms like "limits" were used instead as a way of indicating where consent would end. 
While communication was used to arrange and plan kink sessions, it was also a way of getting to know the person, relating to the previous theme. For example, Caleb said, "There's a high degree of trust involved in any sort of sexual relationship, especially one that involves gear that can go quite badly wrong - I want to know someone at least a bit before I do something like that." Fred also emphasized the importance of establishing trust beforehand, especially if he intended to engage in more "heavy play" (e.g. edge play), so he can discuss "safe words, limits [and] ask how far they can be pushed." He added, "Kink meets can be safer than hook ups - the conversations are longer, and you tend to know more about a person because you chat longer." While most participants were unaware of SSC, they were negotiating safety and consent in their own ways. These extended discussions as a way of developing trust can be understood as indirect discussions of consent, as there is likely an implicit understanding that people would mention what they are interested in doing alongside hard limits. This highlights how the SSC label has fallen out of fashion, because the conversational tone is an implicit way of developing trust and implied consent.

Not all participants used safe words, or indicated they knew about them, and instead preferred open consistent communication beforehand and during kink sessions, with Kyle saying, "I don't bother with safe words because I don't go for anything where I feel my safety will be compromised, or I could just say "it's hurting" etc. I would much rather people openly communicate than bothering with code words."

\section{Laissez-faire and Unstructured Negotiation Approaches}

While most participants described how they implemented some sort of rules, a minority described how they avoided in-depth communication beforehand or discussions of limits. While they may indicate their main kink interests on the SSNS, they would generally meet up and "see what happens" during a kink session. For example, Seamus said, "I just go with the flow really... see what happens." Similarly, when asked about building trust before a scene, David said, "It's common sense I suppose. You can get a gauge on it." The ability to "gauge" a person, was also mentioned by Thomas, who said, "I feel like I'm a fairly good judge of character." Neville described a similar approach to Thomas, but acknowledged the danger of judging people, saying, "If they seem fairly normal, which is a bad measure, it will make me feel more comfortable. I'm not stupid - I know the risks and I tend to ignore them, which is bad."

However, alongside a laissez-faire approach, participants still had some rules, with Dean saying:

I sort of wing it really. I wouldn't let somebody tie me up... You'd also have to be insane to let somebody tie you up in your own house - but that's common sense. I don't do drunk sex and I definitely don't do drunk kink. I avoid drugs as well. I don't hook up with people from a night out... Most of my knowledge has come from meets though - finding out in the moment how to do it.

These participants tended to engage in kinks which could be deemed as less risky, such as power exchange without physical restrictions, or more fetishistic type behaviors, suggesting that 
participants had already considered the risks and deemed them low enough to not explicitly discuss them. However, research into sexual consent more generally highlights how verbal and behavioral cues can often be misinterpreted (Jozkowski \& Peterson, 2013).

\section{Conclusion}

This study explored how kinky gay and bisexual men negotiate consent and the risks associated with kink activities when planning kink hook ups through SSNS. While academics and activists stress the importance of SSC and RACK, particularly in kink venues, most participants reported not having heard of these terms before. Furthermore, some participants stated they were more laidback when engaging in kink. Therefore, there is a potential disconnect between popular kink discourses on safety and consent, and how kink is conducted, particularly when exploring how risk and consent are explored in home venues compared to public kink venues. While at one level this is a disconnect in terminology, it also speaks to deeper differences in conceptualizing and communicating safety, consent, and trust. There is also more emphasis on spontaneity and indirect discussion which serves to distance further from organized kink community sessions where SSC and RACK are emphasized.

Participants avoided using the term consent in their online discussions when planning kink hook ups. Instead, participants described activities they were interested in and limits, or things they will not do. These conversations were less formal than previous research into how kinky individuals negotiated planned activities and consent (e.g. Rubin, 1991; Sagarin et al., 2019), but still a way of establishing trust. While participants did not use SSC or RACK, their engagement in kink more closely reflected the 4Cs framework (Williams et al., 2014). Participants emphasized the importance of communication in kink; negotiated consent through describing their interests and limits; and were cautious in who they engaged in kink with. Further research could apply the 4Cs framework to kink settings, particularly expanding on the role of caring.

The results of this study may be partly due to the sample consisting of gay and bisexual men, and the experiences of straight kink practitioners may be different. This can be explained somewhat through comparing two popular kink SSNS aimed at the two populations: FetLife predominantly caters to straight kink communities and emphasizes the importance of interactions through forums and organizing munches (regularly non-sexual events for members to meet offline and socialize); while Recon, a kink SSNS for gay and bisexual men, tends to focus more on the individual interactions between its members. For gay and bisexual men, kink may predominantly be about the sex and the activities (Wignall \& McCormack, 2017, while for straight kink practitioners, kink could be framed as a ritual which encompasses the pre-activity discussions as part of the kink session (see Sagarin et al., 2015).

Interestingly, this study identified another layer of risk navigated by participants when planning kink activities through SSNS - the risks associated with chatting and meeting others online. Participants placed great importance in verifying the genuineness of their potential kink partner. Indeed, participants created tasks to verify someone's identity and took safety precautions when meeting others. Future research should acknowledge the importance of the internet for kinky individuals and how the use of SSNS creates new challenges and risks. 
Specifically, research could explore how communication of interests and limits on SSNS prior to engaging in kink is executed in person, focusing on the concept of ongoing consent (see Beres, 2007).

\section{References}

Beres, M. (2007). 'Spontaneous' sexual consent: An analysis of sexual consent literature. Feminism \& Psychology, 17(1), 93-108. https://doi.org/10.1177/0959353507072914

Bezreh, T., Weinberg, T., \& Edgar, T. (2012). BDSM disclosure and stigma management: Identifying opportunities for sex education. American Journal of Sexuality Education, 7(1), 37-61. https://doi.org/10.1080/15546128.2012.650984

Braun, V., \& Clarke, V. (2006). Using thematic analysis in psychology. Qualitative Research in Psychology, 3(2), 77-101. https://doi.org/10.1191/1478088706qp063oa

Coppens, V., Ten Brink, S., Huys, W., Fransen, E., \& Morrens, M. (2020). A Survey on BDSM-related activities: BDSM experience correlates with age of first exposure, interest profile, and role identity. The Journal of Sex Research, 57(1), 129-136. https://doi.org/10.1080/00224499.2018.1558437

Döring, N. (2009). The Internet's impact on sexuality: A critical review of 15 years of research. Computers in Human Behavior, 25(5), 1089-1101. https://doi.org/10.1016/j.chb.2009.04.003

Downing, L. (2007). Beyond safety: Erotic asphyxiation and the limits of SM discourse. In D. Langdridge \& M. Barker (Eds.), Safe, Sane and Consensual: Contemporary Perspectives on Sadomasochism (pp. 119-132.) London: Palgrave.

Dunkley, C. R., \& Brotto, L. A. (2019). The Role of Consent in the Context of BDSM. Sexual Abuse. Online first. https://doi.org/10.1177/1079063219842847

Graham, B. C., Butler, S. E., McGraw, R., Cannes, S. M., \& Smith, J. (2016). Member perspectives on the role of BDSM communities. The Journal of Sex Research, 53(8), 895-909. https://doi.org/10.1080/00224499.2015.1067758

Jozkowski, K. \& Peterson, Z. (2013). College students and sexual consent: Unique insights. Journal of Sex Research, 50(6), 517523. https://doi.org/10.1080/00224499.2012.700739

Kaak, A. (2016). Conversational phases in BDSM pre-scene negotiations. Journal of Positive Sexuality, 2(3), 47-52.

Kieran, R., \& Sheff, E. (2016). How Did it Hurt?: distinguishing between Intimate Partner
Violence and BDSM in relationships. In P. Karian (Eds.), Critical \& Experiential: Dimensions in Gender and Sexual Diversity (pp. 141-159). Hampshire, UK: Resonance Publications Ltd.

Krueger, R. (2010a). The DSM diagnostic criteria for sexual sadism. Archives of Sexual Behavior, 39(2), 325-345. https://doi.org/10.1007/s10508-009-9586-3

Krueger, R. (2010b). The DSM diagnostic criteria for sexual masochism. Archives of Sexual Behavior, 39(2), 346-356. https://doi.org/10.1007/s10508-010-9613-4

Langdridge, D. \& Barker, M. (Eds.). (2013). Safe, sane and consensual: Contemporary perspectives on sadomasochism. Palgrave Macmillan.

Lauckner, C., Truszczynski, N., Lambert, D., Kottamasu, V., Meherally, S., SchipaniMcLaughlin, A. M., ... \& Hansen, N. (2019). "Catfishing," cyberbullying, and coercion: An exploration of the risks associated with dating app use among rural sexual minority males. Journal of Gay \& Lesbian Mental Health, 23(3), 289-306. https://doi.org/10.1080/19359705.2019.1587729

Lindemann, D. (2011). BDSM as therapy? Sexualities, 14(2), 151-172. https://doi.org/10.1177/1363460711399038

Moser, C., \& Kleinplatz, P. J. (2007). Themes of SM expression. In D. Langdridge \& M. Barker (Eds.), Safe, Sane and Consensual: Contemporary Perspectives on Sadomasochism (pp. 35-54.) London: Palgrave.

Newmahr, S. (2011) Playing on the edge: Sadomasochism, risk and intimacy. Bloomington, IN: Indiana University Press.

Pitagora, D. (2013). Consent vs. Coercion: BDSM Interactions Highlight a Fine but Immutable Line. The New School Psychology Bulletin, 10(1), 27-36. https://doi.org/10.1037/e543732013-004

Prior, E., \& Williams, D. (2015). Does BDSM power exchange among women reflect casual leisure? An exploratory qualitative study. Journal of Positive Sexuality, 1, 12-15.

Rubin, G. (1991). The catacombs: A temple of the butthole. In M. Thompson (ed.) Leatherfolk: 
Radical sex, people, politics and practice. Boston, MA: Alyson.

Sagarin, B. J., Lee, E. M., Erickson, J. M., Casey, K. G., \& Pawirosetiko, J. S. (2019). Collective Sex Environments Without the Sex? Insights from the BDSM Community. Archives of Sexual Behavior, 48(1), 63-67. https://doi.org/10.1007/s10508-018-1252-1

Sagarin, B. J., Lee, E. M., \& Klement, K. R. (2015). Sadomasochism without sex? Exploring the parallels between BDSM and extreme rituals. Journal of Positive Sexuality, 1(3), 32-36.

Shindel, A. W., \& Moser, C. A. (2011). Why are the paraphilias mental disorders?. The Journal of Sexual Medicine, 8(3), 927-929.

Simula, B. (2019). Pleasure, power, and pain: A review of the literature on the experiences of BDSM participants. Sociology Compass, 13(3), e12668.

Stein, D. (2002). Safe sane consensual: The making of a shibboleth. [Online editorial]. Retrieved from http://www.boybear.us/ssc.pdf

Steinmetz, C. \& Maginn, P.J. (2014) The landscape of BDSM venues. In P.J. Maginn and C. Steinmetz (Eds.), (Sub)urban Sexscapes: Geographies and Regulation of the Sex Industry (pp. 117-137) Abingdon: Routledge.

Sprott, R. A., \& Williams, D. J. (2019). Is BDSM a sexual orientation or serious leisure?. Current Sexual Health Reports, 11(2), 75-79.
Weinberg, T. S., Williams, C. J., \& Moser, C. (1984). The social constitutes of sadomasochism. Social Problems, 31, 379-389.

Weiss, M. (2011). Techniques of Pleasure: BDSM and the Circuits of Sexuality. Duke University Press.

Wignall, L. (2019). Pornography Use by Kinky Gay Men: A Qualitative Approach. Journal of Positive Sexuality, 5(1), 7-13.

Wignall, L. (2017). The Sexual Use of a Social Networking Site: The Case of Pup Twitter. Sociological Research Online, 22(3), 21-37. https://doi.org/10.1177/1360780417724066

Wignall, L., \& McCormack, M. (2017). An Exploratory Study of a New Kink Activity: "Pup Play." Archives of Sexual Behavior, 46(3), 801811. https://doi.org/10.1007/s10508-015-0636-8

Williams, D. J., Thomas, J. N., Prior, E. E., \& Christensen, M. C. (2014). From "SSC" and "RACK" to the "4Cs": Introducing a new framework for negotiating BDSM participation. Electronic Journal of Human Sexuality, 17(5), 1-10.

Zambelli, L. (2017). Subcultures, narratives and identification: An empirical study of BDSM (bondage, domination and submission, discipline, sadism and masochism) practices in Italy. Sexuality \& Culture, 21(2), 471-492. 